\title{
Bioscience-bioethics and life factors affecting reproduction with special reference to the Indigenous Australian population
}

\author{
Irina Pollard \\ Department of Biological Sciences, Macquarie University, Sydney, NSW 2109, Australia \\ Correspondence should be addressed to Irina Pollard; Email: ipollard@rna.bio.mq.edu.au
}

\begin{abstract}
The demand for equality of recognition or respect is the dominant passion of modernity. The 20th century experienced a giant leap in technological inventiveness and ruthless use of technological power. In the 21st century, human welfare and environmental wellbeing demand fundamental political appraisal. We have the means, if we choose, to eradicate poverty and to responsibly protect the global environment. However, economic, political and cultural systems act to differentially allocate the benefits and risks for growth between socioeconomic groups. For example, it is a matter of pride that the neonatal mortality rate in affluent societies has dropped substantially since the late 1970s. However, the level of infant mortality (three times the national average) and low birthweight (13\%) among the Indigenous Australian population is the highest in the country. With hindsight we now know that is the inevitable legacy of Australia's colonial history. Chronic physical and psychological stress is recognized as an important etiological factor in many lifestyle diseases of the cardiovascular, immune and reproductive systems. Diseases of adaptation are further advanced by non-adaptive lifestyle choices, depression, alcoholism and other drug dependencies. This review describes the principles of bioscience ethics and targets equity issues as they affect human reproduction across generations with particular reference to the Indigenous population of Australia. The review also considers ways we may advance global and cultural maturity from the Indigenous Australian perspective and proposes an ecologically based model of preventative care. If we are to embrace fundamental social change and protect future children without threatening parents' basic freedoms, then new beliefs and priorities - based on a compassionate understanding of biological systems - must evolve from the general public. Belief in human rights arising from a sense of human dignity is a collective outcome originating from individual commitment. The golden rule; that is, Nature's principle of reciprocity, is fundamental in bridging the gap between knowledge and effective action.

Reproduction (2005) 129 391-402
\end{abstract}

\section{Introduction}

Being able to put aside one's self-centered focus and impulses has social benefits:it opens the way to empathy, to real listening, to taking another person's perspective.

Empathy... leads to caring, altruism, and compassion. Seeing things from another's perspective breaks down biased stereotypes, and so breeds tolerance and acceptance of differences. These capacities are ever more called on in our increasingly pluralistic society, allowing people to live together in mutual respect and creating the possibility of productive public discourse. These are basic arts of democracy. (Goleman 1996)

Researchers, since the early 1950s, have identified key factors in the generation and maintenance of physical, psychological and social wellbeing. The now famous, ground-breaking research, collectively identified as the Whitehall Studies, resulted in many surprising insights, the most notable being that a sense of control over our lives promotes wellbeing more powerfully than an appropriate command over behaviours such as smoking, diet and exercise (Marmot \& Wilkinson 1999). When focusing on lifestyle diseases such as heart disease, cancer, gastrointestinal disturbances, diabetes or depression, adult health should be evaluated in the context of family and community life, socioeconomic hierarchies as well as important incidents in childhood and prenatal development. The many-faceted Whitehall investigations meticulously recorded the lives of cohorts of British civil servants from different socioeconomic hierarchies. The studies emphasized that lower social standing gave less opportunity and training to influence life's events. It is not the high-powered executive but the worker below, who has very little flexibility in decision-making and ways of achieving set work targets, who succumbs to stress-related 
disease (Marmot \& Feeney 1997, Singh-Manoux et al. 2003). Self-trust is empowering as it provides confidence from the freedom to construct solutions suitable for life's challenges. However, when an individual learns that an outcome is independent of his or her reaction, it has profound emotional and physical effects (Stansfeld et al. 1999, McEwen \& Lasley 2003). Insufficient self-control of ones life creates an overall powerlessness - or learned helplessness - which shapes the social health continuum (McEwen 1998a, 1998b, 2004). Being at the bottom of the social scale, whether provoked by poverty (lower income, lower education, poorer medical care, poorer housing), or advanced by harmful lifestyles (drug dependence, social disengagement), is associated with high rates of morbidity and mortality.

Numerous other sources have confirmed the Whitehall findings that the greatest effects on individual and community health result from environmental degradation and social injustice operating in concert (Donohoe 2003). Lack of control over one's life synergizes harmful dynamics of marginalization, alienation, resentment, depression and environmental deterioration. Effective raising of consciousness, on the other hand, is contingent on all voices being heard, acknowledged and valued, and depends on all community sectors being able to autonomously define their needs in their own way. Robust autonomous decision-making is only achievable when 'specialist' information becomes a resource readily available to the whole community (Ife 1995). Effective reform should reflect the collective outcome of shared community commitments rather than the dictates of authority figures representing senior managers, politicians, doctors, scientists, educators or religious leaders. Communities where newly evolved information is freely shared resemble more closely Nature's fundamental design principle based on cooperation, biological feedback, adaptation to changing conditions and ecological diversity (Pollard 2003a). Nature's evolutionary principle is also fundamental to the universal principle of ethics dubbed the golden rule or 'do unto others as you would have them do unto you'. The golden rule adaptively bridges the gap between knowledge and action - just as biological diversity based on mutualism provides ecological stability so diversity of ideas based on compassionate cooperation provides cultural stability.

The principles of bioscience ethics (Pollard 1999, 2002a) described below will be developed targeting equity issues as they affect human reproduction across generations. The transgenerational legacy of poverty and drug abuse will be particularly explored with reference to Australia's Indigenous population - the most oppressed, disadvantaged and powerless in our affluent multicultural society.

\section{Bioscience ethics - a brief description of the activity}

Technologies, all by-products of science, have redefined how we live, work, fight, relax and communicate with one another. These technologies have provided a previously unimaginable standard of living, but also unprecedented destructive powers. Paradoxically, it is not science but the use or abuse of science that challenges us to react responsibly. When scientific discovery in any discipline is applied its focus shifts, incorporating functions that require value judgements, interactions with belief systems and political forces. Thus, complex modern science creates educational, ethical, legal and social challenges which need to be consistently considered at local, national and international levels. Because modern science and its applications empowers ethics to play a greater and greater role in legal, medical, scientific and policy agendas worldwide, there is a wide-ranging need to find new ways of 'knowing' which can effectively create a scientifically informed and ethically involved community. But how to promote an in-depth understanding of complicated biological information so that ethically responsible positions can be developed?

In order to revise closely held traditional values in the search for a bioethics in tune with present-day reality, we have to appreciate that science and technology is a major force driving contemporary social change. As a concerned scientist, however, I became increasingly aware of the persistence of restrictive subject boundaries that curtailed full and clear information transfer across relevant disciplines. Yet, without such free and accurate access to scientific, medical and technological expertise, enduring social reform would be impeded. So I planned to develop an unencumbered secular forum for discussing practical matters of individual and collective concern. The operating term, coined bioscience ethics (Pollard \& Gilbert 1997), which involves understanding of the biological systems impinging on our lives, has worked well as the accepted interface between applied science and applied bioethics. Life, Love and Children: a Practical Introduction to Bioscience Ethics and Bioethics (Pollard 2002a) is a guide to the essentials of bioscience-bioethics. Biosciencebioethics' major elements are increased understanding of biological systems, responsible use of technology, and reassessment of ethnocentric debate in tune with new scientific insights.

Bioscience ethics readily gained transdisciplinary status as it adapted to different fields including - to my delight - embracing the demands of business bioscience ethics (Eaton 2004). Like the childrens' game cat's cradle, bioscience ethics has fixed posts (stated above) but its configuration within is infinitely malleable. In science, new data can at any time overturn established theory, law or dogma. This is how scientific research provides a selfcorrective mechanism free from out-of-date constraints. Thus, new understanding gained from science and 
technology generates ethical maturity more powerfully than mindlessly following the 'right' dictates of the time. In this context it seems appropriate to quote Darryl Macer: 'A mature society is one which has developed some of the social and behavioral tools to balance bioethical principles, and apply them to new situations raised by technology' (Macer 1998, p 84). Biosciencebioethics involves not only respect for rights and responsibilities, but also includes abstract qualities such as truth, gratitude, guilt, love, communication, consensus and compromise - effective mechanisms for dealing with ethical pluralism. Fundamental to this process, if the bioethical discussion is to be relevant to our knowledge-based lives, is the search for high biological understanding.

Commitment to transform society will not come through some fixed ideology but through general education with a scientific basis (Pollard 2004). The increasing flood of new information produced by modern science and technology changes prevailing ethico-social mores that, in turn, power new ideas as to how best manage changing conditions - and this is where bioscience ethics can assist.

The following contextualizes bioscience-bioethics for the readership of this journal specializing in reproduction.

\section{The first Australians}

This section exposes the reprehensible poverty experienced by large sections of Australia's Indigenous people consequent on past inequities and present marginalization and neglect. However, it has not all been negative since in the last 30 years or so Indigenous people have mobilized in ingenious ways to advance recognition and equal opportunity. For example, the 'Freedom Ride' of the 1960s condemned Australia's version of apartheid and called for social equality; in the 1970s the establishment of the socalled Tent Embassy outside Parliament House in Canberra demanded political recognition; the 1980s - the period of Australia's bicentennial - saw the insertion of black Australian history into the white colonial narrative; and since the 1990s Indigenous people have engaged in every aspect of the country's cultural, political, social and economic life. By asserting their self-determination in so many different contexts, Indigenous Australians are reflecting resilience and determination to overcome the legacies of an oppressive colonial history. However, regardless of progress being made by prominent Indigenous leaders and the goodwill generated between Indigenous and non-Indigenous Australians, there is still a very long way to go before we can achieve social equity and equality of opportunity.

Australia has the enviable reputation of being the land of opportunity. What is not so readily acknowledged is that in the land of opportunity we have failed to bridge the equity gap between Indigenous and non-Indigenous Australians; thereby forfeiting the dominant passion of modernity - promoting equality of opportunity and fair division of resources. From the Australian Aboriginal perspective, inequities generated in the past carry adverse consequences to this day. Past inequities can conveniently be summarized as a series of dispossessions of land, culture, beliefs and practices, identity, children, self-esteem and systematic institutionalization, exclusion and genocide all perpetrated by the in-coming settlers (Smallwood et al. 1997, Grove et al. 2003).

Prior to the traumatic upheavals caused by the incoming Europeans, Aboriginal people lived a traditional way of life for at least 60000 years. This life involved migrating across designated land regions - as affirmed by tribal organization and traditional land rights - to acquire food and shelter. The whole continent was sub-divided into areas inhabited by numerous language, tribal and nation groups. For example, the population of New South Wales was at least 100000 with many tribal, clan and language groupings. With the arrival of the Europeans, this way of life was abruptly disconnected since the early settlers of 1788 assumed that failure to cultivate land negated ownership of it. Consequently, colonial Australia was founded on the myth of terra nullius (uninhabited land) where the early settlers did not recognize any pre-existing law by which the Aboriginal groups held title to land, or rights to its resources. According to international law at the time, the terra nullius declaration legitimated the dispossession of Aboriginal people and allowed the settlers to claim ownership over land and resources on the assumption that it belonged to no one.

Federation in 1901 signalled further historic inequities toward Aboriginal people that reverberate to the present day. Aboriginal people were excluded from citizenship by the Constitution of the Australian Federal Parliament in 1901 and prohibited from voting in Federal elections. This attempt to eradicate Indigenous Australians by dissolving their identity as a people was a crime for which we have to carry responsibility now and into the future.

The health status of Aboriginal and Torres Straight Islander people is a discredit to all Australians. From the Australian Bureau of Statistics we can find the following information. Fifteen percent of households with Indigenous person(s) are considered overcrowded, requiring at least one extra bedroom, compared with $4 \%$ of other households. The level of infant mortality in the Indigenous population is three times the national average. Babies weighing less than $2500 \mathrm{~g}$ at birth are classified as being of low birth weight; and in 2001, babies of Indigenous mothers were twice as likely to be of low birth weight (13\% of births) than babies of non-Indigenous mothers $(6 \%)$. In 2001, the percentage of Indigenous adults classified as overweight or obese was $61 \%$ compared with $48 \%$ of non-Indigenous adults. Infectious diseases and lifestyle illnesses, such as cardiovascular disease, diabetes, cancer and renal disease, are significantly more common in the Indigenous population. The poor health status of Indigenous Australians is emphasized by the fact that, in 2001, they were admitted to hospital more often than non-Indigenous people across all age groups. The life expectancy 
for Aboriginals is $15-20$ years below that of the general population; $45 \%$ of Aboriginal men die before the age of 45 , and $34 \%$ of women fail to reach the same age. These statistics place Aboriginal life expectancy well below third-world standards; a person from Nigeria or Bangladesh can expect to live about 10 years longer than an Indigenous Australian.

Despite these confronting statistics, little is being done to rectify the health of Indigenous Australians. The government still spends less per capita on Indigenous people than it does on the rest of the Australian population - 74 cents on Indigenous Australians for every \$1 spent on the rest of the population. One percent of the national health budget goes to Aboriginal health - for $2.4 \%$ of the population. Aboriginal children are at a serious disadvantage at school because of entirely preventable or controllable health problems such as simple eye and ear infections, asthma and diabetes. Basic preventative medicine is also neglected; for instance, only $46 \%$ of Indigenous children under 7 years of age were immunized for Haemophilus influenza type B in 2001, compared with the non-Indigenous rate of $73 \%$. Drug and alcohol abuse and high rates of unemployment among Aboriginals are severe social problems within the Aboriginal communities. It seems as if we have forgotten that the fundamental right to health and wellbeing, taken for granted by the rest of Australia, belongs to all Australians.

Education is a long-term casualty of the living conditions described above where the Aboriginal school retention rate is $25-50 \%$ less than for other youths and university attendance in 2001 was 5\% compared with the general population's $23 \%$. As a result, Indigenous people in the labour force are almost three times more likely than non-Indigenous people to be unemployed or employed in a casual, low-income capacity. Much of the inequality within modern Australia is not so much to do with political disadvantage, but more to do with a lack of opportunity. Neglect of education automatically reduces employment opportunities, which in turn undermines socioeconomic status and community health. Overall, Aboriginal people in Australia are less well off than indigenous people in other countries. For example, in 1981 Aboriginals were employed at only $58 \%$ the rate of other Australians, whereas African- and Indian Americans were employed at 93 and $84 \%$ the rate of all Americans (Broome 1994). While some argue that these appalling statistics are attributable to incompetence innate to the Aboriginal Nation, they are really a transgenerational reflection of neglect.

In fairness it needs to be stated that socioeconomic deprivation causes comparable transgenerational effects wherever communities suffer similar stresses (see the section on Drug addiction and reproduction from the transgenerational perspective, below). For example, the lifelong accumulated experiences of racial discrimination by African-American women constitutes an independent risk factor for preterm and low-birth-weight deliveries (Rosenberg et al. 2002, Collins et al. 2004) and self-reported experiences of racial discrimination adds to black/white disparities in perinatal outcomes (Mustillo et al. 2004) such as preventable risk factors of homicide and unintentional injury (Jain et al. 2001). As summarized in the introductory sections, the conditions under which people live and the ways in which they behave have a significant bearing on their reproductive health. Reproductive health is conditional on the degree that we have control over our lives and is, characteristically, undermined by the stresses of poverty and environmental degradation.

Significant in the modern context are the freedoms within the biological-political rights continuum. Biological rights include, in broad terms, civil and political rights such as the right of self-determination, the right to participate in cultural and political life and equality before the law, and freedom of movement and association. Full rights participation, or otherwise, involves the socioeconomic health continuum with its entitlements to education and healthcare, and respect for relationships to land and its natural heritage. Biological rights have also been referred to as natural rights because there are certain natural instincts or tendencies in human nature which must be respected by legislation (Ritchie 1952). The principles intrinsic to bioscience-bioethics are integral in upholding the human rights continuum, as illustrated in Fig. 1.

From the human-rights perspective it is obvious that basic services such as education, healthcare, housing and infrastructure are fixed biological rights and should not be considered a part of welfare or be confused with welfare reform. Increased scientific, social and environmental awareness is the key to adaptive change.

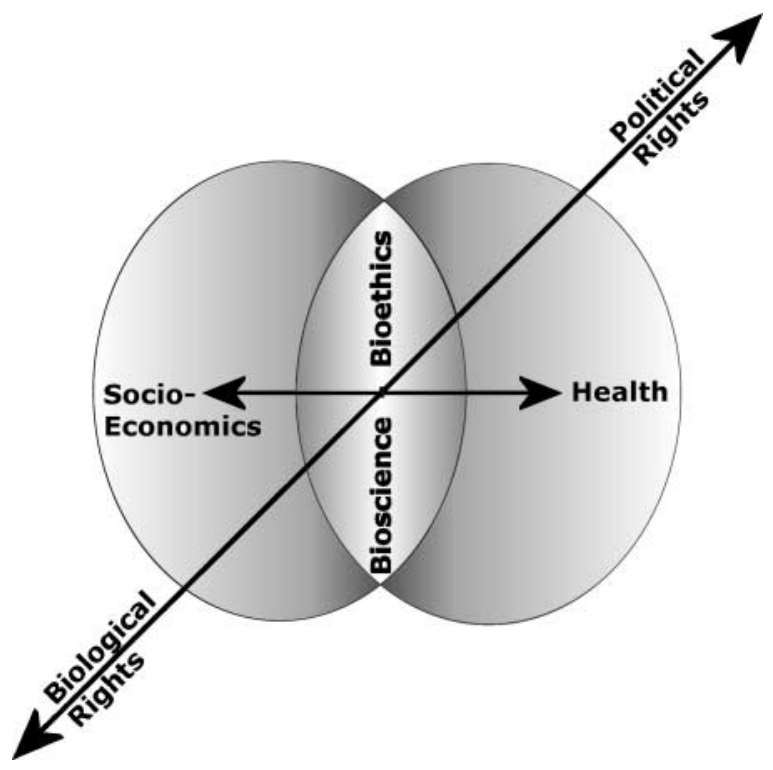

Figure 1 Bioscience-bioethics seamlessly bonds the biological-political and socioeconomic health rights continua. Full rights participation involves the socioeconomic health continuum with its entitlement to education, healthcare and respect for relationships to land and its natural heritage. 


\section{The physiology of stress}

In changing environments, where emotional/physical stability is threatened, compensating homeostatic mechanisms are activated to adapt to the changing conditions. This is known as reactive homeostasis, the stress response or the General Adaptation Syndrome (GAS). The GAS is a non-specific alarm reaction eliciting a generalized increased arousal promoted through specific neurophysiological responses dealing with the reasons for the alarm (Pollard 1994a). When the GAS is activated the cerebral cortex (the analytical or conscious brain), the limbic system (the emotional brain) and the hypothalamic-pituitary-adrenal axis, or stress axis, are mobilized. Normally the stress response is adaptive because extra physiological resources are mobilized to optimally deal with the stress and enhance survival. Initially the physiological mobilization is mediated by the sympathetic nervous system with the release of adrenaline; subsequent back-up is provided by the hypothalamic-pituitary-adrenal axis with glucocorticoid cortisol in humans - release (Fig. 2). Increased cortisol secretion in response to stressful stimuli is one of the principal adaptive responses to stress as it resets the adaptation priorities crucial to coordination of the stress response (Carrasco \& Van de Kar 2003, Ursin \& Eriksen 2004). The coordinated responses are composed of alterations in behaviour, autonomic function and the secretion of multiple hormones and neurohormones.
It is well recognized that chronic or long-term physical/ psychological stress is an important etiological factor in many human diseases, including those of the cardiovascular and immune systems, cancer, gastric ulcerations, hypertension, diabetes, depression and psychoses (Majewska et al. 2002, Ursin \& Eriksen 2004). The diseases of adaptation are commonly advanced by nonadaptive lifestyle choices relating to diet, exercise and substance abuse. The GAS homeostatic mechanisms are characteristically activated regardless of whether the stimulus is real and life-threatening or, for example, chemically induced. This is because the emotional limbic brain, central in the stress response, also serves as the prime target for consciousness-changing/mood-altering substances (Marinelli \& Piazza 2002, Pollard 2003b). Psychostimulants such as cocaine, for example, dramatically increase glucocorticoid secretion via the limbic system (Baumann et al. 1995, Broadbear et al. 1999, Goeders 2002). The functional compartments of the limbic brain include the thalamus, hippocampus, amygdala, hypothalamus and pituitary gland.

\section{Addiction: the chicken-and-egg argument}

In circumstances of heightened, prolonged stress and weakened means of defence, the sufferer may seek the escape that mind-altering, psychoactive substances can provide (Leshner \& Koob 1999, Vetulani 2001).

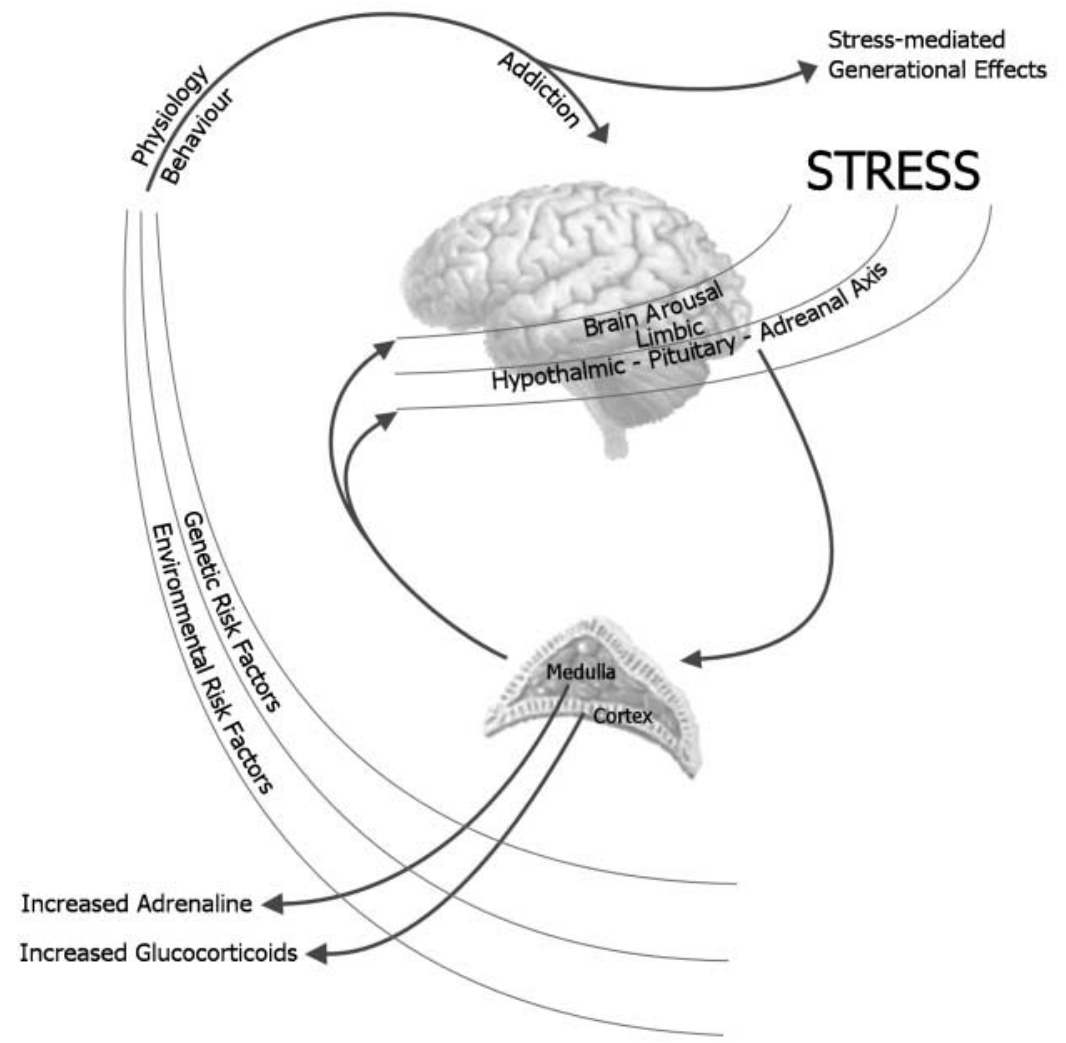

www.reproduction-online.org
Figure 2 The General Adaptation Syndrome (GAS). When the stress response or GAS is activated the cerebral cortex, the limbic brain and the hypothalamic-pituitary-adrenal axis are mobilized. These homeostatic mechanisms are activated regardless of whether the stimulus is real and life-threatening or chemically induced. Changed GAS-activated hormonal profiles during the reproductive cycle can precipitate a broad spectrum of adverse outcomes representing both morphological and physiological or other functional deficits on development of the embryo, fetus and infant. 
Simply expressed, those who become dependent on alcohol or drugs are using these substances as a medication to calm feelings of anxiety, anger or depression (Nestler 2000). Differences in health often have their origin in early life. For instance, an association has been made between chemically dependent women seeking counselling for problems related to substance abuse, and their childhood sexual abuse (Simmons et al. 1996). Similarly, men are more likely to seek help for the consequences of sexual abuse (depression, alcoholism) than for the abuse itself. It may be that survivors of sexual abuse are uncomfortable discussing these matters, or do not view their current drug problems as connected to earlier abuse. Several hundred seventh- and eighth-grade students were tracked for 2 years and it was found that those who reported higher levels of emotional distress subsequently had the highest rates of substance abuse (Tschann et al. 1994). For most alcoholics and drug abusers, the beginnings of addiction can be traced to teen years, though few of those experimenting end up as alcoholics or drug abusers. By the time students leave high school, over $90 \%$ have tried alcohol, yet only about $14 \%$ eventually become alcoholics; of the millions of Americans who experimented with cocaine, fewer than 5\% became addicted (Goleman 1996). However, the years of experimentation also coincide with the reproductive years and an increasingly important issue is the increased use of the assisted reproductive technologies to treat infertility. About one-third of all patients referred for fertility treatment have a significant history of drug exposure (Van Dyke et al. 1985, Van Dyke \& Eberly 1990), reinforcing the view that drug exposure is an important consideration in all at-risk groups (Binetti 2004).

We may wonder why the majority of young people are able to experiment with drugs and alcohol without becoming addicted, while others become dependent almost from the start. It should be kept in mind that poverty itself delivers emotional blows to children: poorer children at age 5 are already more fearful, anxious and sad than their better-off peers, and have more behaviour problems - a trend that continues through the teen years. The stress of poverty corrodes family life resulting in fewer expressions of parental warmth, more depression in mothers (who are often single and jobless) and a greater reliance on harsh punishments, perpetuating social inequalities in health and wellbeing (Kristenson et al. 2004).

The self-medication theory of stress alleviation may not follow a direct relationship in every case. For instance harmful effects from recreational drugs are invisible and cumulative; thus, casual drug consumption for recreational purposes may risk compensatory stress-mediated deregulation of key neurochemical pathways risking depression in formerly healthy individuals with no inherent environmental or genetic risk factors (Pollard 2003b). The conundrum is exemplified by increasing evidence that regular cannabis (marijuana) use and

Reproduction (2005) 129 391-402 depression are associated (Castle \& Murray 2004). There are varying reasons why cannabis use and depression might be associated - cannabis use may precipitate depression or depressed individuals may seek cannabis to improve their mood. Alternatively, there may be similar predisposing factors causing an individual to use drugs and also be depressed. The distinction between the drugcentred theory (externally imposed factors) and the individual-centred theory (genetic susceptibility) may seem purely academic. However, it is not trivial when one considers the possibility of an association between purely recreational drug use causing a congenital susceptibility to drug abuse in a subsequent generation.

From the perspective of the brain, the phenomenon of drug addiction can be seen as the perfect integration of biological and behavioural factors (Fig. 2). Since the brain maintains stability by recruiting the GAS homeostatic mechanisms irrespective of the challenge, it accommodates to artificial chemical stimuli by common stress-combating neurobiological processes (Maldonado 2003). Each drug has its own mechanism of action(s) resulting in the distinctive drug experience. In addition, many drugs of potential abuse, such as nicotine, marijuana, alcohol, cocaine and heroin, have a common effect on the dopaminergic pathways causing a rise in the neurochemical dopamine. Dopamine, serotonin and noradrenaline are the three principal neurotransmitters of the emotional brain that balance the chemistry of mood. Dopamine is involved in the control of numerous functions, including the normal experience of pleasure. Apart from being the reward system of the brain, dopamine also functions as a main neurohormone mediating neural interactions with the pituitary gland which controls metabolism, growth and reproduction (Pollard 2002b, 2003b). Importantly, drug-mediated stress adversely affects fertility and development through well-documented physiological, neurobiological and hormonal mechanisms (Pollard 1994a). Cortisol hypersecretion, in particular, interferes with practically every link in the chain of reproductive physiology and behaviour.

\section{Drug abuse among Indigenous and non-Indigenous Australians}

The Australian population, like many Western societies, most commonly uses and abuses legal drugs, particularly alcohol and tobacco; these drugs are associated with more chronic illness, disease, accidents, social problems, unemployment and days off work than all other drugs together (Brown et al. 1986, Brady 1992). Approximately $80 \%$ of adult Australians use alcohol and $10 \%$ of adults aged 25-64 years are regarded as being at risk because they regularly consume more than five drinks a day (Brown et al. 1986). Aboriginal people in Australia also use mainly the legal drugs - alcohol, tobacco, analgesics, solvents and kava (made from the root of the pepper plant 
Piper methysticum) - although illegal drug use among urban Aboriginals has also been reported (Brady 1992). In remote areas, availability narrows the range of substances used; however, alcohol, tobacco, inhalants (particularly petrol), kava and methanol are regularly available, even in remote bush communities. Kava is legally imported into Australia as a food beverage and is popular in coastal communities of the Northern Territory (Alexander et al. 1987). The pharmacological actions of kava are as a local anaesthetic, a centrally acting muscle relaxant and as a sedative. Kava, which is widely used by Pacific Islander people, is considered harmless if taken in moderation with a balanced diet. However, studies have found that heavy Aboriginal users are underweight and suffer poor health which may include liver damage (Mathews et al. 1988). For reasons of general availability, cheapness and lack of access to other substances, the practise of inhaling volatile substances, specifically petrol, is more prevalent in remote Aboriginal communities than in urban or rural populations (Brady 1992).

Currently, cannabis (Cannabis sativa) is the most widely used illicit substance in the world. Although the drug has been used for centuries, more informed discussion about whether it should be legalized, or at least decriminalized, is needed. As noted above people who suffer psychotic illness are far more likely to consume cannabis than the general population, but the reasons are controversial. Important controversial issues include whether a discrete 'cannabis psychosis' exists, whether cannabis can actually cause schizophrenia and whether there are adverse effects on mood such as anxiety, panic and depression (Castle \& Murray 2004).

Drug use in Western societies is often interpreted as a solution to individually experienced pressures and strains and does not appear to be the prerogative of any particular section of society. For example, while the 19th-century labouring classes in England used gin, the educated and privileged of that era used ether and cocaine nowadays, marijuana and cocaine use is widespread among the so-called middle classes (Pollard 1994b). Nevertheless, a different set of criteria is proposed to explain the antecedent causes of Aboriginal drug use and abuse. These relate to dispossession, colonization, poverty and rapid social change; that is, externally imposed factors. However, overemphasizing externally imposed factors to explain serious social problems may prove counterproductive as, by implication, the Aboriginal is marked as passive victim of historical events, further accentuating feelings of helplessness. The disease model, on the other hand, dramatically individualizes the problem and by relieving the bearer of any responsibility further amplifies the perception of helplessness. Even more sinister, the disease model relieves society of blame since Mother Nature has programmed humans to take drugs. In conclusion, it can be accepted that a broad and complex range of personal and social conditions contribute to drug use and abuse.

\section{Drug addiction and reproduction from the transgenerational perspective}

Since epigenetic effects can be operative at any time during the differentiation of the gametes, the health and living conditions of both parents from the time of gamete formation to the conception of the offspring are crucial, as is the mother's situation during pregnancy and lactation. There are aspects of early development which, if uncorrected perinatally, may have long-term effects upon the individual. Fetuses have mechanisms by which they adapt to deteriorating environmental conditions brought about by drug abuse, disease, nutritional deprivation and nonadaptive lifestyles. Adaptation is subject to genetic variability and, if the limits of genetic adaptability are exceeded, fetal growth retardation and/or organ damage may result. Should epigenetic influences adversely affect the sexual differentiation of the fetal germ cells, then a changed genetic programme may be perpetuated in the offspring of subsequent generations making it possible for the grandparents' lifestyle status to influence the health and wellbeing of their grandchildren. To summarize: a major teratogenic insult during the first 2 weeks of embryonic life is usually embryotoxic, but if the embryo survives, no organ-specific anomalies result. Organ differentiation spans embryonic weeks $3-8$ and during this time the human embryo is especially susceptible to teratogens which may cause germinal and/or somatic mutations. Organogenesis is followed by organ growth, when a teratogen can deleteriously affect growth of the entire fetus or of a particular organ or organ system but usually does not produce a specific malformation. Specific effects cannot be excluded, however, since the development of eyes, ears, teeth, external genitalia and the central nervous system extends well into the fetal period. The final severity of the effect resulting from a certain teratogen depends on individual genetic predisposition, reflected in cell- and tissue-specific repair processes, and whether the defect can be transmitted to a subsequent generation (Fig. 3).

It is sobering to note that increased intergenerational risk of preterm delivery and low birth weights have been documented in African-American third-generation children born of parents of high socioeconomic status (Foster et al. 2000). It should also be noted that certain behavioural anomalies may take more than a generation to discover. Conversely, reproduction under good conditions creates a positive force in shaping human identity.

Although substance use has been a worldwide problem at all levels of society since ancient times much recent attention has focused on the use of legal and illegal substances during the preconceptional and prenatal periods. Consequently, numerous research studies and reviews have highlighted effects of the drugs most frequently used, nicotine, alcohol, marijuana, opiates and cocaine, on maturing gametes, the fetus, neonate and, when possible, the long-term medical and transgenerational problems (Leech et al. 1999, Bard et al. 2000, Pollard 2000). 


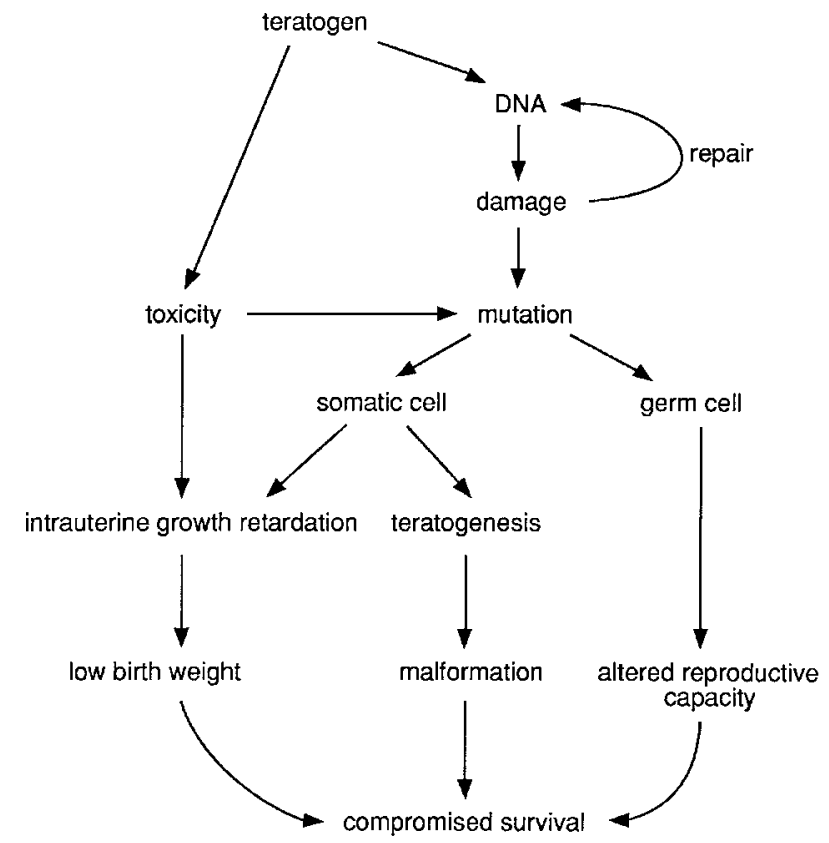

Figure 3 The long-term effects of prenatal insult. A teratogen is any agent introduced during the period spanning germ-cell differentiation to the end of prenatal life that causes morphological, functional or behavioural change in the offspring. Should the germ line be involved, the next and subsequent generations may also be implicated. Reproduced from I. Pollard 1994b A Guide to Reproduction, Social Issues and Human Concerns. Cambridge: Cambridge University Press, p 357.

The full damage caused by prenatal exposure to poisons such as lead, cocaine, alcohol and marijuana cannot be determined until the children are expected to perform behavioural tasks involving attention processes such as learning and memory, and everyday skills like driving. Environmental stressors that cause long-term alterations in fetal brain structures and functions are typically associated with disturbances in the normal development of autonomic regulation. These disturbances are mediated through neurotransmitter systems that are intimately involved in the regulation of the stress response (Gordon 2002, Kofman 2002, Thadani 2002). For example, impaired emotional regulation in infants has been associated with changes in the dopamine transporter system (Gill et al. 1997). Further, gestational/delivery complications, prenatal drug use (including smoking), low socioeconomic status, marital and family discord, maternal psychopathology and paternal criminality have all been cited as risk factors for physical, academic and social-emotional problems in childhood (Biederman et al. 1995, Mclntosh et al. 1995, Milberger et al. 1996, Conners et al. 2004).

It is well established that exposure of both males and females to hazardous chemicals and drugs during the reproductive cycle can precipitate a broad spectrum of adverse outcomes representing morphological, physiological or other functional deficits on development of the embryo, fetus and infant. Such effects manifest themselves through reduced fertility, early miscarriage, fetal death, malformation, retarded growth and organ dysfunction together with delivery of small, intrauterine-growthretarded, weaker infants that are slower in development. Growth-retarded infants also have a higher than normal risk of developing diseases of adaptation such as hypertension, ischaemic heart disease and diabetes in adult life (Pollard 1994a, 2000). It is important not to overlook paternal drug-use habits when evaluating long-term pregnancy outcomes. For example, Little \& Sing (1987) found an average $137 \mathrm{~g}$ reduction in birth weight among infants whose fathers drank regularly (average of two or more drinks daily or binge drinking) in the month before conception; the effect was independent of maternal alcohol or other drug use. That acute and chronic alcoholism is associated with decreased synthesis of testosterone, testicular atrophy, decreased sperm number and motility, and increased appearance of abnormal sperm forms is well established (Irwin et al. 1988, Gavaler \& Van Thiel 1989). However, less is known about the physiological effects of moderate levels of alcohol consumption and whether stress might provide a context within which alcohol effects are exacerbated.

The association between drug consumption during pregnancy and increased risk of any single congenital abnormality in the offspring cannot be assessed accurately due to the heterogeneity of the risk factors and of the innate genetic strengths or weaknesses of the drug-exposed fetus. However, brainstem immaturity and drug withdrawal in infants born to drug-addicted mothers aggravates episodes of apnoea (cessation of breathing) which may result in sudden infant-death syndrome (SIDS). Prenatally drugexposed infants suffer a 5-10-times-increased incidence of SIDS (Alessandri et al. 1996, Golding 1997). Prenatal immune-system programming is also very important in the development of allergies such as asthma. Infants with a raised level of cord serum IgE - an immune marker of sensitization to allergens and asthma - were $66 \%$ more likely to develop asthma by 10 years of age (Sadeghnejad et al. 2004).

Petrol contains many toxic hydrocarbons such as benzene, toluene and xylene. Nowadays we use lead-free fuel but most of the petrol inhaled in the regions under consideration used to be leaded petrol, and chronic sniffers thus suffered the physical consequences associated with lead poisoning as well as the toxic volatile hydrocarbons. Alarmingly, the use of leaded petrol as an inhalant by young Aboriginal people has continuing effects associated with latent reproductive health. More than $90 \%$ of lead accumulated in the body during pre-adult years is stored in the skeleton. Bone remodelling to alleviate a calcium deficiency during pregnancy and lactation releases accumulated lead previously immobilized in the skeleton (Wardaguga \& Dawumal 1980).

The developing nervous system is a primary target site for lead-induced toxicity and congenital central nervous 
system defects. In a fetus there is no blood-brain barrier to lead and other xenobiotics, whereas in later life the blood-brain barrier helps to partially protect the brain from environmental toxins. Significantly, behavioural alterations seen following developmental exposure to organic tetraethyl lead contained in leaded petrol retards brain growth and are accompanied by a plethora of neuropathies identified as tremors, hyperactivity, social aggression and seizures in postnatal life (Lawrence \& Harry 2000). Postnatal lead poisoning in children can also lead to permanent cerebral damage. Petrol sniffers are young adult and adolescent Aboriginals typically between the ages of 10 and 25. Symptoms associated with hydrocarbon toxicity are aggravated by the presence of other stresses and lung infections such as pneumonia are frequently observed in solvent abusers (Fornaazzari 1988). Figure 4 provides a summary overview of the broad domains affecting the prospects for the fostering or the curtailment of individual health and wellbeing.

\section{Bridging the socioeconomic divide in contemporary Australia}

The differential allocation of risks and benefits for growth between differing socioeconomic groups is central to bioscience-bioethical concern. Both a harsh colonial history and self-sustaining inequities are responsible for many of the contemporary problems of Australian Aboriginal children and young adults. We know that children who have experienced a good prenatal environment and were well nurtured in their early years have better outcomes throughout their lives. They do better in school, have higher self-esteem, fewer social, health and behavioural problems and are less likely to become teenage parents, abuse drugs or be involved in crime. We also know that lack of control over ones life engages harmful dynamics symptomatic of marginalization, alienation, resentment, depression and environmental deterioration,

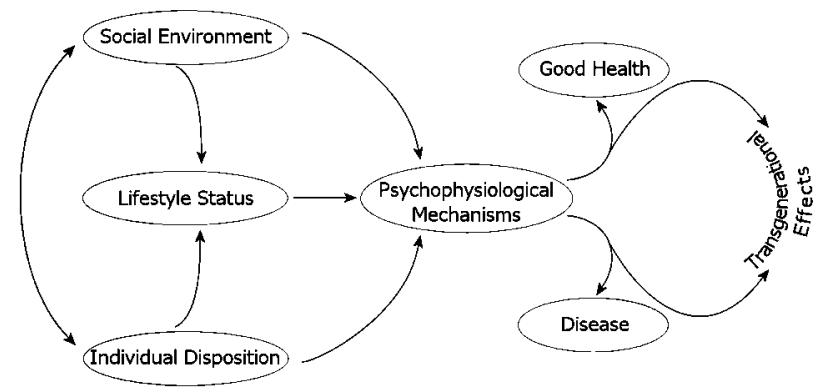

Figure 4 An overview of the broad domains of variables affecting health and wellbeing or the onset of disease. Individual-environment interactions shape the social health gradient via psychophysiological mechanisms which either weaken individual genetic susceptibilities to disease or elicit a strong positive response influencing health and wellbeing. A subsequent generation may be influenced by the degree of fostering or curtailment of individual parental health. and that these harmful dynamics are self-perpetuating across generations. Many lines of research have made the connection between unwanted births and the offspring's greater than expected risk of criminality (Singer et al. 1979) and that domestic violence and abuse is a strong motivation among women seeking an abortion (Glander et al. 1998).

Reproductive risk, particularly among teenage mothers, reflects low socioeconomic status, inappropriate lifestyles and high levels of distress. Persistent powerlessness in Australia's indigenous populations is a shameful consequence of the failure of political, religious, health and legal institutions to bridge the gap between knowledge and effective action. Given scientific acumen and good will, it is possible to simply choose to prevent, postpone or skilfully control the worst consequences of poverty, depression, child neglect and drug dependence. Personal mastery has already been placed on top of the priority list in sickness, so why give it so little emphasis on the continuum of wellness? The uneven distribution of common biological rights has serious psychological, social and economic implications for the nation as a whole. We have the knowledge; all we need is sufficient emotional intelligence to compassionately understand social and ecological systems. Since research has provided a solid scientific basis for assessing reproductive outcomes, re-evaluated bioethical principles can now be utilized. These bioethical principles should seek the individual's commitment to the development of an effective education program that assures good scientific understanding in order to generate universal preventative care, and clearly state its strong disapproval to the needless handicap of the fetus.

\section{An ecologically based model of care based on bioscience ethics}

Health of the last generation begins well before conception. It has been repeatedly demonstrated that if the parents' health is good, or consciously improved before conception, many subsequent problems can be prevented. Given a minimum standard of living, preconceptional care is easy and can also be pleasant; exercise, fresh air and a healthy diet significantly reduce the social and health risks to the future child. When the factors associated with reduced reproductive potential are examined, it must be concluded that public healthcare and intensive education of the population most likely to be at risk are the most effective preventative measures. Governments should take the required measures giving special attention to the education of young people so that they can exercise a responsible attitude to themselves and their children. Translating preventative care into action requires an educational framework, which recognizes the ethical obligation that each of us is custodian of the next and subsequent generations. Practical principles of bioscience ethics might provide a satisfactory scientific framework 
activating the acceptance of reproduction as a privilege, rather than a right; a right all too often trivialized.

Importantly, health resources must be allocated on the basis of need, and Indigenous people must be involved in designing and implementing the solutions. All societies provide special rights to specific groups to ensure equal outcomes for all. That is why we have wheelchair access and designated parking for disabled people and diesel fuel subsidies for farmers. Health and living standards of Indigenous Australian people are the worst in the developed world, so special measures are required to address the underlying causes of such severe disadvantage. In order to destroy inequality there must be a 'fair go' for all Australians. Reconciliation is possible only when people make it their concern and actively work for it. In particular, medical and biological issues to do with health and wellbeing of parents and children need to be addressed and the provision of health and health education expanded for all citizens.

If society's priority were to maximize avoidance of preconceptional prenatal/neonatal harm, the most efficient route would be through improvements to the general quality of life, by eliminating the worst environmental pollution and the stresses of poverty, which impair responsible parental care. An ecological model of care would concentrate on lifestyle factors such as diet, exercise, stress reduction, environmental quality, housing and workplace safety, which are crucial in determining our overall health and genetic resilience (Pollard 2002a).

The ecologically based model of care does not intend that educational reform be uniform; rather its framework should incorporate regional diversity and pluralistic problem-solving in tune with ethnically diverse populations. Part and parcel of raising consciousness is that all voices are heard, acknowledged and valued. Indigenous Australians have shown how it is possible to live in harmony with the natural environment incorporating ecological imperatives and values as well as providing and meeting the basic human needs through community-based social, economic and political structures. Indigenous Australians are an important source of wisdom because their values, social structures and cultural traditions clearly point the way to alternatives from which mainstream Western society has much to learn. This is being increasingly recognized within the ecological movement, and it is beginning to be acknowledged that in many cases Indigenous people's spiritual and social values form a more solid basis for tackling social problems than do the conventional mechanism of the welfare state.

The 20th century experienced a giant leap in technological inventiveness and ruthless use of technological power. The anticipation for the 21 st century is that a critical mass of humans will demand reconciliation by creatively engaging in social reform furthering human evolution toward emotional maturity. Since it is through a sense of control over our lives that we gain higher levels of personal achievement, health and wellbeing, it may be that the material wealth now enjoyed by a significant proportion of people, particularly in industrialized nations, will provide the necessary leisure for intellectual and spiritual development. Freedom from want may provide a breathing space for our further evolution.

Henry Marsh (Marsh 1997) realistically dubbed our recurring basic wants the wheel of needs'. When our basic biological determinants of happiness or needs are not being met, the result is pain but pursuing our pain falsely by, for example, drug abuse, prevents us from confronting the source of our pain and enjoying being well. We have four basic biological needs; to live, to love, to have variety and to have self-worth (Fig. 5). To stay alive (need to live) is the most primal of all and represents the need for food, shelter and protection from the elements. The desire for intimacy (need to give and receive love) is the most basic of social needs. The need for variety represents interest and challenge - the spice of life. The need for self-worth assigns meaning to our lives and represents our quest for aesthetics, for spirituality. When we're successful at meeting these basic needs, life has hope, enthusiasm and zest. If any one of these needs is not satisfied life becomes the opposite, risking depression, escapism, emotional distraction and disease.

In addition to the four basic biological needs, there are a further three social needs essential to the development and maintenance of health and wellbeing (Seligman 1995). The need to feel mirrored or empathized with first develops from the parents or other caregivers early in life. Empathy requires that one understands another's experience from that person's perspective and to communicate that empathy or understanding. The need to idealize others whose values and achievements we respect and aspire to provides the basis on which we build optimism and personal ethics later in life. The twinship or connectedness need provides us with the sense of belonging, of being part of a larger community of people (Fig. 5). These

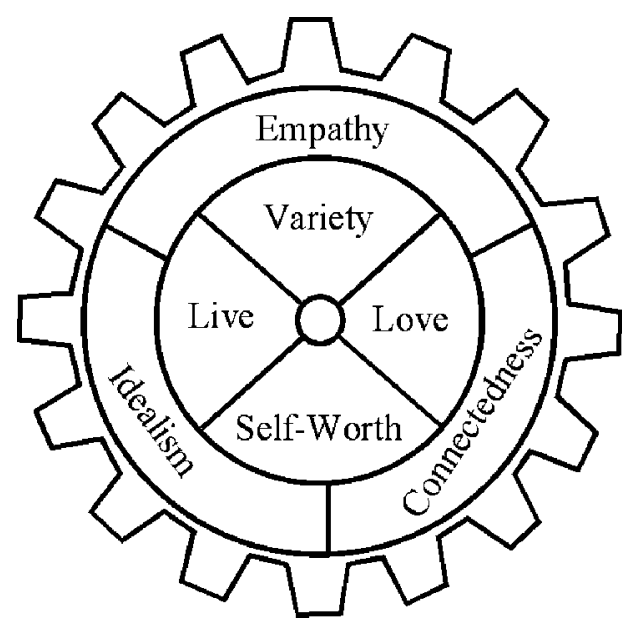

Figure 5 The double needs wheel with the inner circle representing the four basic biological survival needs. The outer needs are subject to having the basic needs satisfied. See text for full explanation. 
more-sophisticated social/cultural needs form the flexible basis of emotional intelligence, but can only be sustained in an environment where basic survival needs have been taken care of.

It seems that we have come full circle and could profit by reconsidering our biological origins. Scientists have drawn attention to the need for parental responsibility to commence well before the child is born. Commitment to the right of humans to express their full genetic potential free from preventable harm is fundamental to the mature society. This is where bioscience-bioethics can assist.

\section{Acknowledgements}

I am grateful to Roger Hiller for his interest and constructive evaluation of the manuscript, and to Ray Duell for the computer-generated illustrations. The authors declare that there is no conflict of interest that would prejudice the impartiality of this scientific work.

\section{References}

Alessandri L, Read A, Burton P \& Stanley F 1996 Sudden infant death syndrome in Australian Aboriginal and non-Aboriginal infants: an analytical comparison. Paediatric \& Perinatal Epidemiology 10 309-318.

Alexander K, Watson C \& Fleming J 1987 In Kava in the North. Darwin: North Australia Research Unit.

Bard K, Coles C, Platzman K \& Lynch M 2000 The effects of prenatal drug exposure, term status, and care giving on arousal and arousal modulation in 8-week-old infants. Developmental Psychobiology $36194-212$.

Baumann M, Gendron T, Becketts K, Henningfield J, Gorlick D \& Rothman R 1995 Effects of intravenous cocaine on plasma cortisol and prolactin in human cocaine abusers. Biological Psychiatry $\mathbf{3 8}$ $751-755$.

Biederman J, Milberger S, Faraone S, Kiely K, Guite J, Mick E, Ablon S, Warburton R \& Reed E 1995 Family-environment risk factors for attention-deficit hyperactivity disorder. A test of Rutter's indicators of adversity. Archives of General Psychiatry $\mathbf{5 2}$ 464-470.

Binetti P 2004 The right to be born and the need to be born healthy: Questions in medical ethics. Clinical Terapeutics 155 89-95.

Brady M 1992 In Heavy Metal: The Social Meaning of Petrol Sniffing in Australia, Canberra: Aboriginal Studies Press.

Broadbear J, Winger G, Cicero T \& Woods J 1999 Effects of selfadministered cocaine on plasma adrenocorticotropic hormone and cortisol in male rhesus monkeys. Journal of Pharmacology and Experimental Therapeutics 289 1641-1647.

Broome R 1994 In Aboriginal Australians. Sydney: Allen \& Unwin.

Brown V, Manderson D, O'Callaghan M \& Thomson R 1986 In Our Daily Fix: Drugs in Australia, Canberra: Australian National University Press.

Carrasco G \& Van de Kar L 2003 Neuroendocrine pharmacology of stress. European Journal of Pharmacology 463 235-272.

Castle D \& Murray R 2004 In Marijuana and Madness: Psychiatry and Neurobiology. Cambridge: Cambridge University Press.

Collins J, David R, Handler A, Wall S \& Andes S 2004 Very low birthweight in African American infants: the role of maternal exposure to interpersonal racial discrimination. American Journal of Public Health $942132-2138$.

Conners N, Bradley R, Mansell L, Liu J, Roberts T, Burgdorf K \& Herrell J 2004 Children of mothers with serious substance abuse problems: an accumulation of risks. American Journal of Drug \& Alcohol Abuse 30 85-100.
Donohoe M 2003 Causes and health consequences of environmental degradation and social injustice. Social Science \& Medicine $\mathbf{5 6}$ 573-587.

Eaton M 2004 In Ethics and the Business of Bioscience. Stanford: Stanford University Press.

Fornaazzari L 1988 Clinical recognition and management of solvent abusers. Internal Medicine for the Specialist 9 99-109.

Foster H, Wu L, Bracken M, Semenya K \& Thomas J 2000 Intergenerational effects of high socioeconomic status on low birthweight and preterm birth in African Americans. Journal of the National Medical Association 92 213-221.

Gavaler J \& Van Thiel D 1989 Alcohol interactions with the reproductive system. In Metabolic and Physiological Effects of Alcohol, pp 81-94. Eds K Crow \& R Batt. Boca Raton, FL: CRC Press.

Gill M, Daly G, Heron S, Hawi Z \& Fitzgerald M 1997 Confirmation of association between attention deficit hyperactivity disorder and a dopamine transporter polymorphism. Molecular Psychiatry $\mathbf{2}$ $311-313$.

Glander S, Moore M, Michielutte R \& Parsons L 1998 The prevalence of domestic violence among women seeking abortion. Obstetrics \& Gynecology 91 1002-1006.

Goeders N 2002 The HPA axis and cocaine reinforcement. Psychoneuroendorinology 27 13-33.

Golding J 1997 Sudden infant death syndrome and parental smoking a literature review. Paediatric \& Perinatal Epidemiology 11 67-77.

Goleman D 1996 In Emotional Intelligence: Why It Can Matter More Than IQ. London: Bloomsbury.

Gordon H 2002 Early environmental stress and biological vulnerability to drug abuse. Psychoneuroendocrinology 27 115-126.

Grove N, Brough M, Canuto C \& Dobson A 2003 Aboriginal and Torres Strait Islander health research and the conduct of longitudinal studies: issues for debate. Australian \& New Zealand Journal of Public Health 27 637-641.

Ife J 1995 In Community Development: Creating Community Alternatives - Vision, Analysis and Practice. Melbourne: Longman Australia.

Irwin M, Dreufus E, Baird S, Smith T \& Schuckit M 1988 Testosterone in chronic alcoholic men. British Journal of Addiction 83 949-953.

Jain A, Khoshnood B, Lee K \& Concato J 2001 Injury related infant death: the impact of race and birth weight. Injury Prevention 7 $135-140$.

Kofman O 2002 The role of prenatal stress in the etiology of developmental behavioural disorders. Neuroscience \& Biobehavioral Reviews 26 457-470.

Kristenson M, Eriksen H, Sluiter J, Starke D \& Ursin H 2004 Psychobiological mechanisms of socioeconomic differences in health. Social Science \& Medicine 58 1511-1522.

Lawrence D \& Harry G 2000 Environmental stressors and neuroimmunotoxicological processes. Brain, Behavior \& Immunity 14 231-238.

Leech S, Richardson G, Goldschmidt L \& Day N 1999 Prenatal substance exposure: effects on attention and impulsivity of 6-yearolds. Neurotoxicology \& Teratology 21 109-118.

Leshner A \& Koob F 1999 Drugs of abuse and the brain. Proceedings of the Association of American Physicians 111 99-108.

Little R \& Sing C 1987 Father's drinking and infant birth weight: Report of an association. Teratology 36 59-65.

Macer D 1998 In Bioethics is Love of Life: An Alternative Textbook. Tsukuba: Eubios Ethics Institute.

Majewska M, Gordon H \& Thadani P 2002 Stress and drug abuse. Psychoneuroendocrinology 27 1-3.

Maldonado R 2003 The neurobiology of addiction. In Addiction: Mechanisms, Phenomenology and Treatment, pp 1-14. Eds W Fleischhacker \& D Brooks. Journal of Neural Transmission $\mathbf{6 6}$ (Suppl.).

Marinelli M \& Piazza P 2002 Interaction between glucocorticoid hormones, stress and psychostimulant drugs. A review. European Journal of Neuroscience 16 387-394. 
Marmot M \& Feeney A 1997 General explanations for social inequalities in health. IARC Science Publication 138 207-228.

Marmot M \& Wilkinson R 1999 In Social Determinants of Health. Oxford: Oxford University Press.

Marsh H 1997 In The Breakthrough Factor. New York: Simon \& Schuster.

Mathews J, Riley M, Fejo L, Munoz E, Milus N, Gardner I, Powers J, Ganygulpa E \& Gununuwawuy B 1988 Effects of heavy usage of Kava on physical health: Summary of a pilot survey in an Aboriginal community. Medical Journal of Australia 148 548-555

McEwen B 1998a Stress, adaptation, and disease. Allostasis and allostatic load. Annals of the New York Academy of Sciences 1 $33-44$.

McEwen B $1998 b$ Protective and damaging effects of stress mediators. New England Journal of Medicine 338 171-179.

McEwen B 2004 Association of depression with medical illness: does cortisol play a role? Biological Psychiatry 55 1-9.

McEwen B \& Lasley E 2003 Allostatic load: when protection gives way to damage. Advances in Mind and Body Medicine 19 $28-33$.

McIntosh D, Mulkins R \& Dean R 1995 Utilization of maternal perinatal risk indicators in the differential diagnosis of ADHD and UADD children. International Journal of Neuroscience $\mathbf{8 1}$ $35-46$.

Milberger S, Biederman J, Faraone S, Chen L \& Jones J 1996 Is maternal smoking during pregnancy a risk factor for attention deficit hyperactivity disorder in children? American Journal of Psychiatry $1531138-1142$.

Mustillo S, Krieger N, Gunderson E, Sidney S, McCreath H \& Kiefe C 2004 Self-reported experiences of racial discrimination and Black-White differences in preterm and low-birthweight deliveries: The CARDIA study. American Journal of Public Health 94 2125-2131.

Nestler E 2000 Genes and addiction. Nature Genetics 26 277-281.

Pollard I 1994a Population dynamics, stress and the general theory of adaptation. In A Guide to Reproduction, Social Issues and Human Concerns, pp 225-248. Cambridge: Cambridge University Press.

Pollard I 1994b Principles of teratology and an update on nicotine, ethanol and caffeine abuse. In A Guide to Reproduction, Social Issues and Human Concerns, pp 353-375. Cambridge: Cambridge University Press.

Pollard I 1999 Warfare fitness enhancement or losing strategy? A bioscience ethics perspective. Eubios Journal of Asian \& International Bioethics 9 50-54.

Pollard I 2000 Substance abuse and parenthood: Biological mechanism - bioethical challenges. Women \& Health $301-24$.

Pollard I 2002a In Life, Love and Children: a Practical Introduction to Bioscience Ethics and Bioethics. Boston MA: Kluwer Academic.

Pollard I 2002 $b$ Substance abuse and parenthood: Biological mechanisms - ethical responsibilities. In Life, Love and Children: a Practical Introduction to Bioscience Ethics and Bioethics, pp 35-56. Boston MA: Kluwer Academic.

Pollard I 2003a Choose between cooperation and annihilation: a mental mapping project towards a more generously directed altruism. Eubios Journal of Asian \& International Bioethics $\mathbf{1 3}$ $44-48$.

Pollard I $2003 b$ From happiness to depression. Today's Life Science $1522-26$.
Pollard I 2004 The evolution of thinking and ideas with special reference to the politics of reproduction. In Challenges for Bioethics from Asia, pp 88-94. Ed. D Macer. Tsukuba: Eubios Ethics Institute.

Pollard I \& Gilbert S 1997 Bioscience ethics - A new conceptual approach to modern ethical challenges. Eubios Journal of Asian \& International Bioethics 7 131-135.

Ritchie D 1952 In Natural Rights; A Criticism of Some Political and Ethical Conceptions. London: Unwin Brother.

Rosenberg L, Palmer J, Wise L, Horton N \& Corwin M 2002 Perceptions of racial discrimination and the risk of preterm birth. Epidemiology 13 646-652.

Sadeghnejad A, Karmaus W, Davis S, Kurukulaaratchy R, Matthews S \& Arshad S 2004 Raised cord serum immunoglobulin E increases the risk of allergic sensitisation at ages 4 and 10 and asthma at age 10. Thorax 59 936-942.

Seligman M 1995 In The Optimistic Child. Sydney: Random House.

Simmons K, Sack T \& Miller G 1996 Sexual abuse and chemical dependency. Implications for women in recovery. Women \& Therapy 19 17-30.

Singer G, Stern Y \& Van der Spy H 1979 Emotional disturbance in unplanned, versus planned children. Social Biology 23 254-258.

Singh-Manoux A, Adler N \& Marmot M 2003 Subjective social status: its determinants and its association with measures of ill-health in the Whitehall II study. Social Science \& Medicine $\mathbf{5 6}$ $1321-1333$.

Smallwood G, White C \& Kotiw M 1997 The relevance of human rights to health status in Australian Aboriginal and Torres Strait Islander Communities. Health \& Human Rights 2 127-136.

Stansfeld S, Fuhrer R, Shipley M \& Marmot M 1999 Work characteristics predict psychiatric disorder: Prospective results from the Whitehall II study. Occupational Environmental Medicine $\mathbf{5 6}$ $302-307$.

Thadani P 2002 The intersection of stress, drug abuse and development. Psychoneuroendocrinology 27 221-230.

Tschann J, Adler N, Irwin C, Millstein S, Turner R \& Kegeles S 1994 Initiation of substance use in early adolescence: the roles of pubertal timing and emotional distress. Health Psychology 13 326-333.

Ursin H \& Eriksen H 2004 The cognitive activation theory of stress: a review. Psychoneuroendocrinology 29 567-592.

Van Dyke D \& Eberly S 1990 Babies at risk: drug abuse and pregnancy. lowa Medicine 80 391-393.

Van Dyke D, Trabilcy E, Moran E \& Hartzog S 1985 Drug and environmental exposure histories in selective patient populations. Journal of Family Practice 1 51-54.

Vetulani J 2001 Drug addiction. Part II. Neurobiology of addiction. Polish Journal of Pharmacology 53 303-317.

Wardaguga M \& Dawumal M 1980 In Petrol Sniffing: Aboriginal Health Workers Third Annual Conference Report. Australia: Alice Springs.

Received 23 November 2004

First decision 17 December 2004

Revised manuscript received 7 January 2005

Accepted 21 January 2005 